\title{
Health-related medium term quality of life in intermediate risk pulmonary embolism in a general ICU
}

\author{
E Portugal Rodríguez*, M Del Valle Ortiz, O Badallo Arévalo, JM Ayuela Azcárate, E Martínez Barrio, \\ A Berrazueta Sánchez de Vega, M Gero Escapa, JA Fernández Ratero, SA Ossa Echeverri, ME Perea Rodríguez, \\ C Carbajales Pérez
}

From ESICM LIVES 2015

Berlin, Germany. 3-7 October 2015

\section{Introduction}

Quality of life (QOL) after an episode of pulmonary embolism (PE) may be influenced by the factors related with the PE and its complications.

\section{Objectives}

The aim is to determine whether poor clinical condition after discharge (6-12 months) of patients with intermediate-risk (IR) PE is influenced by epidemiological and clinical factors, echocardiography (TTE) on admission and/or discharge; analytical and electrocardiographic (ECG); specific treatment and associated complications [1].

\section{Methods}

Descriptive, observational study of patients with IR PE admitted to the ICU during a 5 years period (20102014). IR PE was classified by PESI. QOL was analyzed 6-12 months after discharge, into two subgroups: good clinical condition (no dyspnea, normal life, partial dependence) or poor condition (dyspnea, total dependence). Analysis: Chi square and Fisher exact test. Variables: epidemiological (venous thrombosis, previous embolism, oral contraceptive, immobilization, surgery, smoking, neoplasia, heart and bronchial disease); clinics (syncope, chest pain, heart rate $>110 \mathrm{bpm}$, Fi02 $>30 \%$ ); analytical (troponin, proBNP, D-Dimer, $\mathrm{pH}$, pC02); ECG; TTE (right cavities dilatation (RCD), TAPSE $<15 \mathrm{~mm}$, tricuspid regurgitation (TR), pulmonary hypertension (PHT), Mc.Connell sign); treatment applied (fibrinolysis or anticoagulation only) [2] and complications (mechanical ventilation-MV, bleeding, home 02).

\section{Results}

81 cases of PE; 67 cases IR were selected (56.7\% male). Mean age: $66.31( \pm 16.32)$ years. Two subgroups: $58.5 \%$ had good QOL while $41.5 \%$ had poor condition at 6-12 months from discharge. We related all variables with poor QOL obtaining: no statistically significant relationship (SSR) with epidemiological factors and ECG, correlation with clinical factors: acidosis on admission ( $\mathrm{p}$ 0.001) and Fi02 (p 0.014) and hypercapnia ( $\mathrm{p} 0.028)$ at discharge. TTE factors were analysed: TAPSE, RCD on admission and TR at discharge were SSR with poor QOL ( $\mathrm{p}$ 0.001, p 0.039, p 0.034). There was no association with the treatment applied. We found worst QOL in those who needed MV (p 0.02) had bleeding complications ( $\mathrm{p}$ 0.003) and required home 02 ( $\mathrm{p} \mathrm{0.016).}$

\section{Conclusions}

A poor QOL after IR PE discharge (6-12 months), is related with acidosis, low TAPSE and RCD on admission; need of MV, high Fi02, bleeding and hypercapnia complications during ICU stay; TR and needs of home 02 at discharge.

Published: 1 October 2015

\section{References}

1. Clinical practice guidelines of the European Society of Cardiology for diagnosis and management of acute pulmonary embolism. 2014. 
2. Fibrinolysis for patients With Pulmonary Embolism Risk intermediate-, NEJM. 2014.

doi:10.1186/2197-425X-3-S1-A768

Cite this article as: Portugal Rodríguez et al:: Health-related medium

term quality of life in intermediate risk pulmonary embolism in a

general ICU. Intensive Care Medicine Experimental 2015 3(Suppl 1):A768.

\section{Submit your manuscript to a SpringerOpen ${ }^{\mathcal{D}}$ journal and benefit from:}

- Convenient online submission

- Rigorous peer review

- Immediate publication on acceptance

- Open access: articles freely available online

- High visibility within the field

- Retaining the copyright to your article

Submit your next manuscript at $\gg$ springeropen.com 